\title{
Ovarian Hemangioma: a rare case in a young girl
}

\author{
Meenal M. Patvekar ${ }^{1}$, Dipak S. Kolate ${ }^{1}$, Aditi B. Bhatnagar ${ }^{1 *}$, Charusheela R. Gore ${ }^{2}$
}

\author{
${ }^{1}$ Department of Obstetrics and Gynecology, Department of Pathology, Dr. D Y Patil Medical College, Hospital and \\ Research Institute, Pune, Maharashtra, India
}

Received: 30 July 2015

Accepted: 14 August 2015

\section{*Correspondence:}

Dr. Aditi B. Bhatnagar,

E-mail: aditibhatnagar2510@gmail.com

Copyright: (C) the author(s), publisher and licensee Medip Academy. This is an open-access article distributed under the terms of the Creative Commons Attribution Non-Commercial License, which permits unrestricted non-commercial use, distribution, and reproduction in any medium, provided the original work is properly cited.

\begin{abstract}
The ovary has a rich vascular supply. But the vascular tumors of the ovary are extremely rare. Ovarian masses are mostly discovered accidentally during surgery or imaging. These tumors may rarely be associated with systemic manifestations. Here we report a case of 17 year old young unmarried obese girl who presented with acute pain in abdomen and was treated laproscopically with conservation of ovaries. Histopathology report was suggestive of ovarian haemangioma. The diagnostic challenge and therapeutic rarity of such a tumour in a young unmarried girl has proven to be an exceptional case and an excellent investigative opportunity.
\end{abstract}

Keywords: Ovary, Haemangioma, Vascular, Stromal luteinisation, Laproscopic cystectomy

\section{INTRODUCTION}

The ovary is an organ not accessible to the clinical examination and therefore tumors of ovary pose a challenge for the gynaecologist to diagnose. Ovarian masses are most of the time an accidental finding during an ultrasonography done for another cause or during surgery or autopsy. They may also present as pain in abdomen, bloating and large masses. Ovarian haemangioma may partly be arising as a type of germ cell tumour in ovary and amongst all ovarian masses the most uncommonly found with statistics of only 50 cases reported worldwide. ${ }^{1}$

Here we report a case of 17 year old young unmarried girl who presented with acute pain in abdomen and radiological investigations suggestive of right ovarian mass was treated laproscopically with the aim of conservation of ovary.

\section{CASE REPORT}

A 17 year old unmarried girl admitted with severe pain in abdomen with vomiting. Patient gave history of dragging pain in abdomen since 7-8 days which aggravated on day of admission. Patient was obese with BMI of 30.5 and history of irregular menses since menarche. On examination there was tenderness in right iliac fossa, however no specific mass was palpable.

Her haematological and biochemical investigations were within normal limits. On admission she was treated conservatively with I.V. fluids, analgesics and antibiotics. Her CA 125 levels, alpha-fetoprotein and LDH were within normal limits. Her Ultrasonography revealed a Solid ovarian tumour $10 \times 5.5 \times 5 \mathrm{~cm}$ in diameter with low resistance, vascular flow pattern on Doppler. No evidence of ascites was found and opposite ovary appeared normal. This was followed by MRI which was suggestive of solid right adnexal lesion suggesting a right ovarian lesion of size $9 \times 8.9 \times 7.5 \mathrm{~cm}$.

By the Risk of Malignancy Index (RMI), she was categorized under low risk disease. ${ }^{2}$ Patient underwent laproscopy. Intraoperatively, cyst wall was densely adherent to ovarian tissue. Contents within the cyst were fibrous, highly vascular and reddish-purplish in color. Cystectomy was accomplished; tissue was retrieved and sent for histopathological examination. Perfect 
haemostasis was secured. Both fallopian tubes and left ovary were normal.

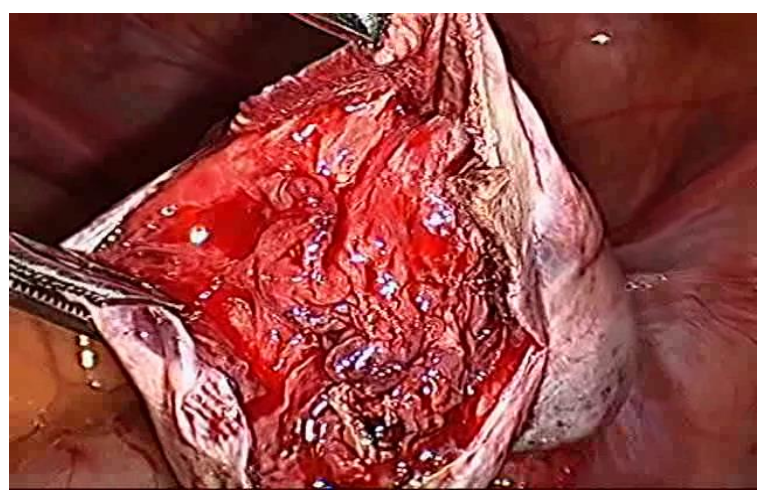

Figure 1: Gross picture showing haemorrhagic surface with a spongy irregular appearance.

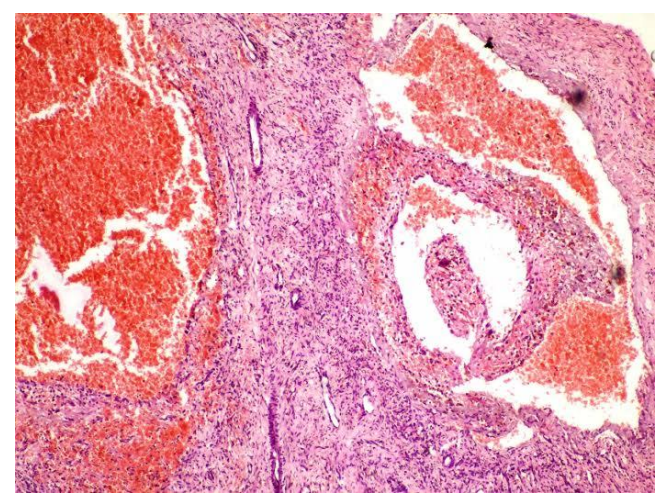

Figure 2: Microphotograph showing large cavernous spaces filled with blood as well as small capillary sized blood channels (H \&E, x 100).

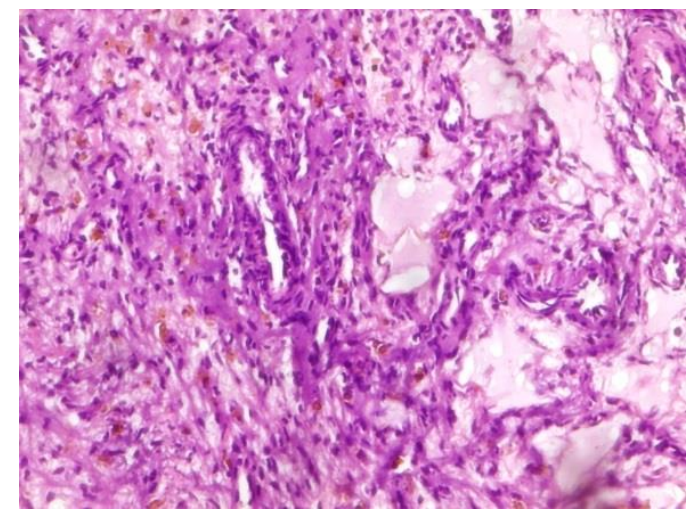

Figure 3: photograph showing many capillaries, thin walled cystic spaces filled with proteinaceous material with haemosiderin laden macrophages in the surrounding stroma (H \&E, x 400).

\section{DISCUSSION}

In 1869 , ovarian haemangioma was first described by Payne. ${ }^{1,3}$ But till date very few cases are reported in literature because of variable size and asymptomatic nature of tumour, and are associated with other genital tract diseases.

Ovarian hemangiomas are reported in wide age group ranging from infancy to 81 years., ${ }^{1,3}$ Ovarian haemangioma can be of variable size ranging from few $\mathrm{mm}$ to $24 \mathrm{~cm}^{1,3}$ These can be seen in any part of the ovary, hilum and medulla being the most common sites. ${ }^{3,4}$ Some cases of bilateral ovarian haemangioma are reported although mostly these are unilateral. ${ }^{1,4,5}$ Histologically these are predominantly cavernous type. ${ }^{3,4}$ Capillary and mixed type are also seen.

Most of them are small tumors with no symptoms, found incidentally at the time of ultrasonography, surgery or autopsy and sometimes with surprising histological diagnosis of hemangiomas. ${ }^{3,4}$ Large lesions may present as adnexal mass, abdominal pain, nausea and vomiting due to ovarian torsion.

Though these haemangioma are benign non-functional tumors, sometimes present as solid ovarian mass with ascites and elevation of CA-125.,6,7 Since ovarian haemangioma are associated with variable age group, treatment is in respect to age, reproductive performance and merits of the patient at presentation. Thus such findings can mislead the diagnosis and there by management.

Lesions may co-exist with other genital malignancies such as endometrial carcinoma, ${ }^{3}$ ovarian carcinoma, carcinoma cervix and endocrine dysfunction like hyperandrogenism, ${ }^{3}$ hyperestrogenism. ${ }^{3,8,9}$ Some of the complications of ovarian haemangioma can be listed as pseudo-Meigs syndrome, ${ }^{10}$ stromal leutinization, ${ }^{11}$ stromal hyperplasia and thrombocytopenia. ${ }^{1,3}$

Histopathogenesis of ovarian haemangioma is topic of debate with many theories coming up. Some haemangioma originate from germ cells as part of a teratoma. $^{9,12}$

In Differential diagnosis non-circumscribed Dilated hilar vessels, Ovarian teratoma ${ }^{9}$ with angiomatosis, Angiosarcoma with invasion atypia, Lymphangioma should be distinguished from Ovarian haemangiomas. ${ }^{4}$ Macroscopically mass was haemorrhagic without any necrosis. Microscopically a cavernous haemangioma of ovary was noticed incidentally.

Lesion is characterized by numerous thin walled vascular channels having different sizes and configurations. Few vascular channels were dilated and filled with RBC's. Single layer of flattened endothelial cells without atypia were lining these vascular channels. ${ }^{9}$ These vessels were intermixed/separated with variable amount of connective tissue without any inflammation or calcification. Before diagnosing the tumour as a pure haemangioma, a thorough microscopic search for teratomatous component is necessary in a hemangiomatous proliferation. ${ }^{1,9,11}$ Ovarian teratomas with prominent vascular component 
are identified by the presence of dermal, adnexal or other ectodermal, endodermal or mesodermal component from pure haemangioma. There was no evidence of any such component in our case and hence was not classified as teratoma.

The pathogenesis of ovarian haemangioma is not yet clearly known, it may rarely be associated with stromal leutinization. $^{3,13}$ In this context, and two hypothesis proposed are whether luteinisation is the stimulator for development of ovarian haemangioma or it is a reactive process. $3,4,14$

Treatment modality of ovarian haemangioma is surgery which in most of the cases results in complete cure. Surgical management in young patients desirous of reproductive function can be treated by laproscopic cystectomy with conservation of ovary. Some cases of ovarian haemangioma have been reported to be a part of teratoma or associated with other genital tract malignancies. ${ }^{4}$ Such patients with completed family and not desirous of reproductive function can be managed by total abdominal hysterectomy with bilateral salpingooophrectomy. ${ }^{4}$

\section{CONCLUSION}

Ovarian haemangioma is benign and often non-functional asymptomatic tumour, presenting in wide age group. Considering their rare occurrence ovarian haemangioma are a diagnostic challenge. It can be managed with different treatment modalities depending upon age and reproductive function. Such cases can be successfully managed laproscopically with conservation of ovary. Follow up: On post-operative day 8 stitches were removed. Stitch line was healthy. Patient was followed up after menses next month. There were no fresh complaints

Funding: No funding sources

Conflict of interest: None declared

Ethical approval: Not required

\section{REFERENCES}

1. Shashikala K, Sharmila PS, Sushma T A, Paul Francis. Ovarian haemangioma with synchronous xanthogranulomatous inflammation-a rare pathological finding. Int $\mathbf{J}$ Health Sci Res. 2013;3(5):116-119.

2. Erhan Aktürk, Riza Efendi Karaca, Ibrahim Alanbay, Murat Dede, Emre Karasahin, Mufit Cemal Yenen, et al. Comparison of four malignancy risk indices in the detection of malignant ovarian masses J Gynecol Oncol v.22(3);2011 Sep.

3. Bolat, Filiz, Serkan Erkanli, and Nazım Emrah Kocer. "Ovarian hemangioma: Report of two cases and review of the literature." Turkish Journal of Pathology. 2010;26.3:264-6.
4. Shirazi B, Anbardar MH, Azarpira N, Robati M. An incidental ovarian mass: A case of ovarian hemangioma with prominent stromal luteinization. Med J DY Patil Univ 2015;8:227-30.

5. Correa-Rivas, María S., Gloria Colón-González, and Humberto Lugo-Vicente. "Cavernous hemangioma presenting as a right adnexal mass in a child." Puerto Rico health sciences journal 22.3 (2011).

6. Erdemoglu, E., Kamaci M, Ozen S, Sahin HG, Kolusari A. "Ovarian hemangioma with elevated CA125 and ascites mimicking ovarian cancer." European journal of gynaecological oncology 27.2 (2005):195-196.

7. Gehrig PA, Fowler WC Jr, Lininger RA. Ovarian capillary hemangioma presenting as an adnexal mass with massive ascites and elevated CA-125. Gynecol Oncol. 2000;76:130-2.

8. Akbulut M, Bir F, Colakoglu N, Soysal ME, Duzcan SE. "Ovarian hemangioma occurring synchronously with serous papillary carcinoma of the ovary and benign endometrial polyp." Annals of Saudi medicine. 2008;28.2:128.

9. Comunoglu, Cem, Latife Atasoy, and Cem Baykal. "Ovarian hemangioma occurring synchronously with contralateral mature cystic teratoma in an 81-yearold patient." Upsala journal of medical sciences. 2010;115.4:297-9.

10. Kaneta, Y., Nishino, R., Asaoka, K., Toyoshima, K., Ito, K., and Kitai, H. Ovarian hemangioma presenting as pseudo- Meigs' syndrome with elevated CA125. J Obstet Gynaecol Res. 2003;29: 132-135.

11. Hatci Bayramoglu, Tayfun Gungor, Murat oz, Nasuh U. Dogan, Huseyin Rehyan, Mustafa Besli. Primary ovarian hemangioma: case report and review of literature. Medical journal of Islamic World of sciences. 2012;20(3):106-10.

12. Gücer, F., Özy1lmaz, F., Balkanl1-Kaplan, P., Mulayim, N., and Aydin, O. Ovarian hemangioma presenting with hyperandrogenism and endometrial cancer: a case report. Gynecol Oncol. 2004;94:8214.

13. Anand MS, Shetty S, Mysorekar VV, Kumar RV. Ovarian hemangioma with stromal luteinization and HCG producing mononucleate and multinucleate cells of uncertain histogenesis: A rare co-existence with therapeutic dilemma. Indian J Pathol Microbiol. 2012;55:509-12.

14. Akbulut, Metin, Zekioglu Osman, Terek Mustafa, Ozdemir Necmettin. Florid vascular proliferation in mature cystic teratoma of the ovary: case report and review of the literature. Tumori 2009;95.1:104.

Cite this article as: Patvekar MM, Kolate DS,

Bhatnagar AB, Gore CR. Ovarian Haemangioma: a rare case in a young girl. Int $\mathrm{J}$ Reprod Contracept Obstet Gynecol 2015;4:1634-6. 